\title{
PAPERS
}

Divisione di

Gastroenterologia, Ospedale

"CSS"-IRCCS, San

Giovanni Rotondo,

Italy

V Annese

A Andriulli

Laboratorio di Motilità Intestinale, Sezione di Gastroenterologia ed

Epatologia,

Dipartimento di

Medicina Clinica e

Sperimentale,

Università di Perugia,

Italy

G Bassotti

Divisione di

Gastroenterologia,

Ospedale Galliera,

Genova, Italy

G Coccia

Servizio di Endoscopia Digestiva, Ospedale S

Raffaele, Milano, Italy

M Dinelli

Divisione di

Gastroenterologia, Ospedale di Avellino, Italy

V D'Onofrio

Servizio di

Gastroenterologia, Ospedale "Cervello", Palermo, Italy

G Gatto

Divisione di Medicina, Ospedale IRCCS "De Bellis", Castellana

Grotte, Italy

G Leandro

Dipartimento di Gastroenterologia, Università di Torino, Italy

A Repici

Reparto di

Gastroenterologia, Policlinico S Marco, Zingonia, Italy

P A Testoni

Correspondence to: Dr Vito Annese, Divisione di Gastroenterologia, Ospedale "CSS"-IRCCS, Viale

Cappuccini, 1- 71013 San

Giovanni Rotondo (Fg), Italy

Accepted for publication 25 November 1999

\section{A multicentre randomised study of intrasphincteric botulinum toxin in patients with oesophageal achalasia}

\author{
V Annese, G Bassotti, G Coccia, M Dinelli,V D’Onofrio, G Gatto, G Leandro, A Repici, \\ P A Testoni, A Andriulli, the GISMAD Achalasia Study Group
}

\begin{abstract}
Background-Intrasphincteric injection of botulinum toxin (Botx) has been proposed as treatment for oesophageal achalasia. However, the predictors of response and optimal dose remain unclear.

Aims-To compare the effect of different doses of Botx and to identify predictors of response.
\end{abstract}

Patients/methods-A total of 118 achalasic patients were randomised to receive one of three doses of Botx in a single injection: 50 $U(n=40), 100 U(n=38)$, and $200 U(n=40)$. Of those who received $100 \mathrm{U}$, responsive patients were reinjected with an identical dose after 30 days. Clinical and manometric assessments were performed at baseline, 30 days after the initial injection of botulinum toxin, and at the end of follow up (mean 12 months; range 7-24 months). Results-Thirty days after the initial injection, $82 \%$ of patients were considered responders without a clear dose related effect. At the end of follow up however, relapse of symptoms was evident in $19 \%$ of patients who received two injections of $100 \mathrm{U}$ compared with $47 \%$ and $43 \%$ in the $50 \mathrm{U}$ and $200 \mathrm{U}$ groups, respectively. Using Kaplan-Meier analysis, patients in the $100 \times 2 \mathrm{U}$ group were more likely to remain in remission at any time $(p<0.04)$, with $68 \%(95 \%$ CI 59-83) still in remission at 24 months. In a multiple adjusted model, response to Botx was independently predicted by the occurrence of vigorous achalasia (odds ratio 3.3 ) and the $100 \times 2 \mathrm{U}$ regimen (odds ratio 3.2 ).

Conclusions-Two injections of $100 \mathrm{U}$ of Botx 30 days apart appeared to be the most effective therapeutic schedule. The presence of vigorous achalasia was the principal determinant of the response to Botx. (Gut 2000;46:597-600)

Keywords: achalasia; botulinum toxin; oesophagus; dose ranging study

Intrasphincteric injection of botulinum toxin (Botx) has been proposed as an effective treatment approach in many patients with oesophageal achalasia ${ }^{12}$ particularly when other therapeutic modalities have failed. ${ }^{3}$ Botx injection is a safe procedure, being associated with few side effects or complications in either low or high risk patients. ${ }^{45}$ Symptomatic improvement occurs in most patients shortly after the initial treatment, and multiple Botx injections are required to maintain efficacy over time. ${ }^{6-8}$ Yet the specific patient characteristics that predict response to Botx remain unclear, and there is no consensus on the optimal dose and the most appropriate treatment regimen.

The aim of this study was to compare the efficacy and safety of different doses of Botx and to identify predictors of response in achalasic patients.

\section{Materials and methods}

PATIENTS

Since January 1997, 118 achalasic patients (62 men, 56 women, age range $18-78$ years) have entered the study: nine patients $(8 \%)$ had undergone a previously unsuccessful treatment, either dilatation $(n=7)$ or myotomy $(n=2)$. All patients underwent clinical evaluation of oesophageal symptoms, barium oesophagram, oesophageal manometry, and upper gastrointestinal endoscopy. Patients younger than 18 years, pregnant women, and those with evidence of oesophageal ulcers, Barrett's oesophagus, oesophageal varices, or oesophageal or gastric carcinoma were excluded.

\section{CLINICAL ASSESSMENT}

Patients were asked to complete a semistructured questionnaire on the presence and frequency of three oesophageal symptoms: dysphagia, regurgitation, and chest pain. ${ }^{37} \mathrm{~A}$ score of 0-3 was attributed to each symptom depending on its occurrence: never, occasionally, more than once a week, or daily. The efficacy of Botx was based on clinical criteria. Response to treatment was arbitrarily defined as a total score of $\leqslant 2$, while a total score of $\geqslant 3$ was considered suggestive of treatment failure (or relapse). ${ }^{37}$ Body weight before and after treatment was also recorded.

\section{BARIUM OESOPHAGRAM}

In all patients a barium oesophagram was performed only at baseline to assess oesophageal diameter.

Abbreviations used in this paper: Botx, botulinum toxin; LES, lower oesophageal sphincter. 
Table 1 Baseline demographic and clinical characteristics of the achalasic patients in each treatment group (mean (SD) or number)

\begin{tabular}{llll}
\hline & $\begin{array}{l}\text { Botx 50U } \\
(n=40)\end{array}$ & $\begin{array}{l}\text { Botx 100 U } \\
(n=38)\end{array}$ & $\begin{array}{l}\text { Botx 200 U } \\
(n=40)\end{array}$ \\
\hline Sex (M/F) & $18 / 22$ & $24 / 14$ & $19 / 21$ \\
Mean age (years) & $54.7(19)$ & $55.5(18.5)$ & $55(18)$ \\
Symptom duration (months) & $34.4(31)$ & $51.9(70)$ & $55(56)$ \\
Previous dilatation/myotomy & $3 / 0$ & $3 / 0$ & $1 / 2$ \\
LES basal pressure (mm Hg) & $36(14.5)$ & $34.8(9.5)$ & $32(8)$ \\
Vigorous achalasia & $14 / 40$ & $11 / 38$ & $11 / 40$ \\
Oesophageal diameter (cm) & $3.9(1)$ & $4.3(1.1)$ & $4.2(0.9)$ \\
Symptom score & $5.3(1.5)$ & $5.4(1.7)$ & $5(1.5)$ \\
Weight loss (kg) & $4.3(4)$ & $4(4.9)$ & $3(3.3)$ \\
\hline
\end{tabular}

Table 2 Post-treatment data for achalasia in each group (mean (SD) or number)

\begin{tabular}{|c|c|c|c|c|}
\hline & $\begin{array}{l}\text { Botx } 50 U \\
(n=40)\end{array}$ & $\begin{array}{l}\text { Botx } 100 \mathrm{U} \\
(n=38)\end{array}$ & $\begin{array}{l}\text { Botx } 200 U \\
(n=40)\end{array}$ & $p$ Value \\
\hline \multicolumn{5}{|l|}{ At 30 days } \\
\hline LES basal pressure $(\mathrm{mm} \mathrm{Hg})$ & $24.3(13)$ & $24.2(10.4)$ & $21(7.3)$ & NS \\
\hline Symptom score & $1.7(1.9)$ & $1.5(1.8)$ & $1(1.2)$ & NS \\
\hline Chest pain after injection & $3 / 40$ & $2 / 38$ & $4 / 40$ & NS \\
\hline \multirow[t]{2}{*}{ Failures } & $10 / 40$ & $6 / 38$ & $5 / 40$ & NS \\
\hline & $\begin{array}{l}50 \mathrm{U} \\
(n=30)\end{array}$ & $\begin{array}{l}100 U \times 2 \\
(n=32)\end{array}$ & $\begin{array}{l}200 \mathrm{U} \\
(n=35)\end{array}$ & \\
\hline \multicolumn{5}{|l|}{ At the end of follow up } \\
\hline Relapses & $14 / 30$ & $6 / 32$ & $15 / 35$ & 0.04 \\
\hline Duration of follow-up (months) & $11.9(6)$ & $12.8(5)$ & $9.7(4.7)$ & NS \\
\hline Cumulative months of remission & 246 & 371 & 206 & 0.01 \\
\hline
\end{tabular}

OESOPHAGEAL MANOMETRY

Oesophageal manometry was performed using an 8 lumen polyvinyl chloride manometric catheter, as previously described. ${ }^{7}{ }^{9}$ Each channel was connected to external pressure transducers and perfused constantly with bubble free distilled water at $0.5 \mathrm{ml} / \mathrm{min}$ by a low compliance pneumohydraulic system. Resting lower oesophageal sphincter (LES) pressure was measured by station pull through. Oesophageal motor activity was evaluated in response to at least 10 wet swallows ( $5 \mathrm{ml}$ of water) administered 30 seconds apart. Patients with a mean oesophageal body contraction amplitude greater than $40 \mathrm{~mm} \mathrm{Hg}$ in the distal two leads were diagnosed as having vigorous achalasia. ${ }^{10}$

BOTULINUM TOXIN INJECTION

Upper gastrointestinal endoscopy was performed under conscious sedation with diazepam $10 \mathrm{mg}$ intravenously. After identification of the LES region, Botx was injected in eight aliquots of $0.5 \mathrm{ml}$ at two different sites (1 $\mathrm{cm}$ apart) of each quadrant. Patients were randomised to receive one of three different doses of Botx (Botox, Allergan Inc, Irvine, California, USA). Group A received $50 \mathrm{U}$, group B $100 \mathrm{U}$, and group C $200 \mathrm{U}$. To investigate if the timing of Botx administration interferes with the duration of its efficacy, responsive patients in group B were reinjected with an identical dose after 30 days. This group of patients was chosen because information on the long term efficacy of a single injection of Botx was available only for doses of 80-100 U. ${ }^{8}$ Patients were allowed to eat the same day and were monitored in hospital overnight.

\section{ANALYTIC STRATEGY}

Clinical assessment of oesophageal symptoms and manometry was performed at baseline, 30 days after the initial injection of Botx, and at the end of follow up (mean 12 months; range 7-24 months). During the follow up period, patients were asked to complete a questionnaire by telephone interview every 30 days, conducted by one of the authors (AA) who was blinded to the treatment regimens. The study was approved and monitored by an ethics committee, and informed consent was obtained from each patient.

\section{STATISTICAL ANALYSIS}

All analyses were performed using BMDP software (University of California). Quantitative parameters are presented as mean (SD). Differences between treatment groups as a percentage of responders were evaluated using Fisher's exact test and Wilcoxon's signed rank test for non-parametric variables. Survival curves were compared using the Kaplan-Meier method which tested the impact of different doses of Botx on the likelihood of remaining symptom free and also a possible single centre effect. For evaluation of independent predictors of response to Botx, we used Cox's proportional hazard modelling. To test for parallelism, the proportional assumption was graphically verified by plotting $\log [-\log$ (survivor function) $]$ against time in groups identified by each covariate. A likelihood ratio test was used to assess the probability of significance of each variable to be entered or removed, with all variables included in the regression model at the start of the analysis. $\mathrm{p}<0.05$ was chosen as significant.

\section{Results}

Table 1 shows that the baseline demographic and clinical characteristics of patients in each treatment group were similar. Symptom score and manometric parameters were not significantly different but patients randomised to receive the higher doses of Botx had a longer duration of symptoms.

On the basis of symptom improvement (score $\leqslant 2$ ) evaluated 30 days after the initial Botx injection, 97 of 118 patients ( $82 \%$; CI 71-90) were considered responders. The proportion of responders was slightly dose related but not statistically significant: $75 \%$ (30/40) of patients who received Botx $50 \mathrm{U}$ responded compared with $84 \%(32 / 38)$ and $88 \%(35 / 40)$ in the $100 \mathrm{U}$ and $200 \mathrm{U}$ groups, respectively. Side effects - most commonly mild and transient retrosternal or epigastric pain sensationwere reported by nine patients and did not appear to be dose dependent.

Table 2 shows that 30 days after Botx injection the improvements in symptom score and LES pressure were similar in all groups. In patients considered responders at 30 days, symptom relapse at the end of follow up was evident in 19\% (CI 5-32) of patients who had received two injections of Botx $100 \mathrm{U}$ compared with $47 \%$ (CI 29-64) and $43 \%$ (CI 26-59) in the $50 \mathrm{U}$ and $200 \mathrm{U}$ groups, respectively. Similarly, the symptom free time was significantly longer in the $100 \times 2 \mathrm{U}$ group relative to the other treatment groups $(\mathrm{p}<0.01)$.

Survival analysis showed that patients in the $100 \times 2 \mathrm{U}$ group were more likely to remain in 


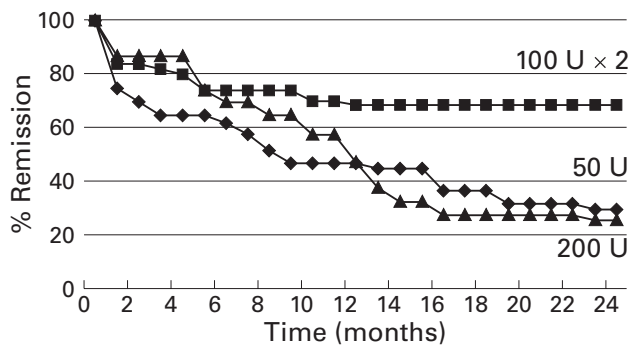

Figure 1 Remission curves using Kaplan-Meier analysis after Botx injection of $50 \mathrm{U}, 100 \times 2 \mathrm{U}$, or $200 \mathrm{U}$ in the three groups of patients, obtained by censoring all non-responders.

remission at any time $(\mathrm{p}<0.04)$, with $68 \%$ (CI 59-83) still in remission at 24 months compared with $29 \%$ and $27 \%$ who received $50 \mathrm{U}$ and $200 \mathrm{U}$, respectively (fig 1 ).

Table 3 compares the demographic, clinical, and manometric characteristics of patients based on their response to Botx at 30 days. Univariate analysis showed that no single baseline variable was associated with response to treatment, except age: the age of responders was greater than that of non-responders $(\mathrm{p}<0.03)$. Thirty days after treatment, LES pressure and symptom scores were significantly reduced in responders compared with nonresponders.

In a multiple adjusted model for evaluation of predictors of efficacy, response to Botx was independently predicted only by the presence of vigorous achalasia (odds ratio (OR) 3.3; $95 \%$ CI 1.3-8) and by treatment regimen (OR 3.2 ; $95 \%$ CI $1.3-7.7$ for the $100 \times 2 \mathrm{U}$ dose). In particular, we also examined if response to Botx was affected by severity of disease: in a subset analysis, 58 of 118 patients ( $49 \%$ ) had a baseline symptom score $\geqslant 6$; the proportion of failures in this subgroup $(20 \%)$ was not significantly different from the $15 \%$ failure rate in the subgroup with less frequent symptoms (score <6) $(\mathrm{p}=0.57)$.

Finally, as approximately $40 \%$ of patients were recruited from a single centre, the results of this centre were compared with those from the other participating centres by KaplanMeier analysis: the respective curves were not different $(\mathrm{p}=0.6)$ (fig 2$)$.

\section{Discussion}

Our study has shown that $\geqslant 75 \%$ of patients with achalasia experienced initial benefit from intrasphincteric injection of Botx with only a

Table 3 Demographic, clinical, and manometric variables in responders and non-responders (mean (SD) or number)

\begin{tabular}{llll}
\hline & $\begin{array}{l}\text { Non-responders } \\
(n=21)\end{array}$ & $\begin{array}{l}\text { Responders } \\
(n=97)\end{array}$ & $p$ Value \\
\hline Sex $(\mathrm{M} / \mathrm{F})$ & $12 / 9$ & $50 / 47$ & $\mathrm{NS}$ \\
Mean age (years) & $49.3(19)$ & $57.5(18)$ & 0.03 \\
Symptom duration (months) & $48(60)$ & $45.5(54)$ & $\mathrm{NS}$ \\
Previous dilatation/myotomy & $3 / 21$ & $6 / 97$ & $\mathrm{NS}$ \\
Vigorous achalasia & $5 / 21$ & $31 / 97$ & $\mathrm{NS}$ \\
Weight loss (kg) & $3(3.9)$ & $3.9(4.3)$ & $\mathrm{NS}$ \\
Oesophageal diameter (cm) & $4.5(1.2)$ & $4(1)$ & $\mathrm{NS}$ \\
Pretreatment LES (mm Hg) & $39.7(15)$ & $33.3(10)$ & $\mathrm{NS}$ \\
Pretreatment symptom score & $5.9(1.2)$ & $5.2(1.6)$ & $\mathrm{NS}$ \\
At 30 days & $36.6(13)$ & $20.5(7.6)$ & 0.001 \\
$\quad$ Post-treatment LES (mm Hg) & $4.4(1.6)$ & $0.8(0.6)$ & 0.001 \\
$\quad$ Post-treatment symptom score & 2 & 7 & NS \\
Chest pain after injection & & & \\
\hline
\end{tabular}

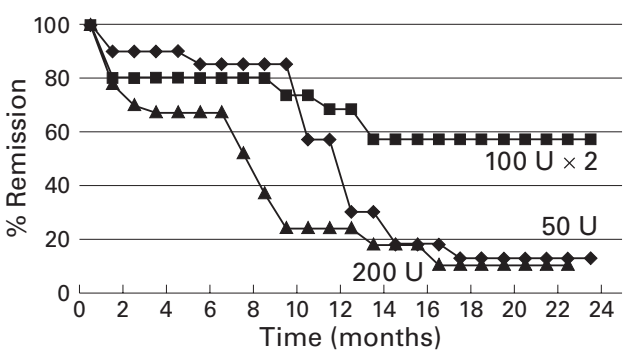

Figure 2 Remission curves by Kaplan-Meier analysis after Botx injection of $50 \mathrm{U}, 100 \times 2 \mathrm{U}$, or $200 \mathrm{U}$ in the three groups of patients, obtained in the main centre of the study (S Giovanni Rotondo). Values did not differ significantly from those of the whole population $(p=0.6)$ or other centres (data not shown).

weak correlation with dose. None the less, at the end of follow up patients who had received two injections of $100 \mathrm{U}, 30$ days apart, exhibited a much lower rate of relapse than patients treated with the same dose in a single injection. Finally, the presence of vigorous achalasia was found to be the principal determinant of the response.

Treatment with Botx is considered standard for various skeletal muscle disorders ${ }^{11}$ but its application for gastrointestinal conditions has been proposed only recently. Specifically, in the case of achalasia it remains unclear if it should be preferred to more definitive modalities of treatment, such as pneumatic dilation or surgical myotomy. On the one hand, Botx represents a specific and selective method of counteracting the neuronal derangement that is the hallmark of achalasia. ${ }^{12}$ In fact, Botx relieves LES pressure through reduction of the excitatory cholinergic innervation of the sphincter. ${ }^{13}$ On the other hand, treatment with Botx is effective only in the short term ${ }^{1-5}$ and repeated injections are needed to maintain remission. ${ }^{6-8}$ This could indicate that Botx is not an ideal treatment ${ }^{14-16}$; more importantly, the specific patient characteristics that predict a better response remain unclear. Moreover, previous studies varied greatly in terms of dose and treatment modality, ${ }^{1-8} 1617$ and consensus on the optimal dose and treatment regimen is lacking.

Our study suggests that there may be a weak and narrow dose dependency of the effect of Botx. A single injection of $50 \mathrm{U}$ was slightly less effective than higher doses but no more patients who received $200 \mathrm{U}$ benefited than those who received $100 \mathrm{U}$.

When we tested the potential benefit of a repeat dose of Botx injection, before symptom relapse, we found that in the group who received a second injection of $100 \mathrm{U}$ of Botx, a greater proportion of patients remained symptom free at the end of follow up than those who received the same dose in a single injection $(19 \%$ v 43\%; $\mathrm{p}<0.04)$. Nearly two-thirds of patients in the $100 \times 2 \mathrm{U}$ group were still in remission at the end of follow up and this is consistent with the rate observed when Botx is injected every time symptoms relapsed. ${ }^{8}$ Finally, the proportion of patients who remained symptom free at the end of follow up did not differ between those who received $50 \mathrm{U}$ or $200 \mathrm{U}$ of Botx. It seems possible that the 
modalities of treatment are more relevant than the total amount of toxin injected.

While it is well known that the effect of a single injection of Botx wanes over time, explanations for this phenomenon are still speculative. It is possible that the atrophy of postsynaptic nerve endings and muscles secondary to block of acetylcholine release at presynaptic sites is reversible. Indeed, in skeletal muscle, new nerve ending sprouts are evident two to three weeks after injection of toxin. ${ }^{18}$ We hypothesise that a similar mechanism may be operative in smooth muscle, and that early administration of a repeat dose of Botx (i.e. within 30 days) would inhibit nerve regeneration thus leading to long lasting symptomatic improvement.

Small number of patients (3-7\%) with skeletal muscle disorders may develop antibodies with repeated Botx injections and in some cases may became resistant to treatment. ${ }^{19} \mathrm{~A}$ higher proportion of antibodies (up to $10 \%$ ) has been reported when higher doses or booster injections of Botx are used. ${ }^{20}$ While the same phenomenon has not been proved for smooth muscle, it cannot be completely ruled out. However, a correlation between detection of antibodies and clinical resistance is not always apparent, whereas patients with proved resistance may benefit from injections with other serotypes of toxin. ${ }^{19}$

The presence of vigorous achalasia was the only independent predictor of response to Botx. Its relevance has been previously reported $^{6}$ but we have characterised its importance more clearly after adjustment for potential confounders. In common with other studies $^{46817}$ responders were significantly older, but in a multiple adjusted model, age itself did not appear to have an independent effect. Finally, a multiple adjusted model and subset analysis excluded the fact that severity of disease influenced the success of treatment.

It is noteworthy that even in the most efficacious treatment group almost $20 \%$ of patients did not experience any benefit. While we cannot exclude the possibility of resistance to Botx ${ }^{18}$ it is likely that the intrinsic characteristics of patients, not taken into account in this study, are important in determining who will respond to treatment.

Our study evaluated the largest series ever of patients with achalasia. Almost $95 \%$ of patients had not received any other treatment for the disease before Botx, and randomisation to different doses afforded comparability of patient characteristics. All patients were evaluated with oesophageal manometry, and remission was ascertained with well established and validated clinical criteria. None the less, some limitations need to be acknowledged. Firstly, although large, our series may not have been sufficient to identify other predictors of response to treatment. Indeed, vigorous achalasia, the only independent determinant identified, was present in less than one-third of cases. In addition, we did not use a control group for treatment and did not consider performing a 30 day sham endoscopy in all patients. While this may have been appropriate, we considered it unethical. Finally, the strategy to reinject with $100 \mathrm{U}$ of
Botx only in those patients who responded at 30 days could have positively biased the results of this regimen. However, a comparative analysis at the end of follow up after censoring nonresponders at 30 days confirmed that $100 \mathrm{U}$ was the most efficacious dose.

In conclusion, our study showed that intrasphincteric injection of Botx is a feasible, safe, and effective treatment of achalasia in the short and medium term. Although a weak dose correlation emerged, the dose of $100 \mathrm{U}$ and a second injection at 30 days should be the preferred regimen. Future studies are warranted to validate this regimen and to establish its cost effectiveness compared with conventional treatment.

The following investigators participated in the GISMAD (Gruppo Italiano per lo Studio della Motilità dell'Apparato Digerente) Achalasia Study Group (the numbers of patients Digerente) Achalasia Study Group (the numbers of patients
recruited in each centre is given in parentheses): V Annese, $G$ recruited in each centre is given in parentheses): V Annese, G
Lombardi, A. Andriulli, San Giovanni Rotondo (48 patients); G Lombardi, A. Andriulli, San Giovanni Rotondo (48 patients); G
Bassotti, E Distrutti, A Morelli, Perugia (nine patients); G Coccia, E Bovero, Genova (20 patients); M Dinelli, S Passaretti, Milano (five patients) ; V D' Onofrio, G Iaquinto, Avellino (10 patients); G Gatto, V Peri, Palermo (seven patients); A Repici, A Ferrari, Torino (14 patients), P A Testoni, F Bagnolo, Zingonia (five patients)

The authors thank Ermelinda De Santo for skilful technical support, Dr Giovanni Gambassi for reviewing the English version of the manuscript, and Dr Stelio Giaccari for referring some patients.

1 Pasricha PJ, Ravich WJ, Hendrix TR, Sostre S, Jones B, Kalloo AN. Treatment of achalasia with intrasphincteric injection of botulinum toxin. A pilot trial. Ann Intern Med 1994;121:590-1.

2 Pasricha PJ, Ravich WJ, Hendrix TR, Sostre S, Jones B, Kalloo AN. Botulinum toxin for the treatment of achalasia. N Engl f Med 1995;322:774-8.

3 Annese V, Basciani M, Lombardi G, et al. Perendoscopic injection of botulinum toxin is effective in achalasia after failure of myotomy or pneumatic dilation. Gastrointest failure of myotomy or

4 Cuilliére C, Ducrotté P, Zerbib F, et al. Achalasia : outcome of patients treated with intrasphincteric injection of botulinum toxin. Gut 1997;41:87-92.

5 Gordon JM, Eaker EY. Prospective study of esophageal botulinum toxin injection in high-risk achalasia patients. Am f Gastroenterol 1997;92:1812-17.

6 Pasricha PJ, Rai R, Ravich WJ, Hendrix TR, Kalloo AN. Botulinum toxin for achalasia: long-term outcome and predictors of response. Gastroenterology 1996;110:1410-15.

7 Annese V, Basciani M, Perri F, et al. Controlled trial of botulinum toxin injection versus placebo and pneumatic dilation in achalasia Gastroenterology 1996:111:1418-24.

8 Annese V, Basciani M, Borrelli O, Leandro G, Simone P, Andriulli A. Intrasphincteric injection of botulinum toxin is effective in long-term treatment of esophageal achalasia. Muscle Nerve 1998;21:1540-2.

9 Bassotti G, Battaglia E, Debernardi V, et al. Esophageal dysfunction in scleroderma. Relationship with disease subsets. Arthritis Rheum 1997;40:2252-8.

10 Goldenberg SP, Burell M, Fette GG, Vos C, Traube M. Classic and vigorous achalasia: a comparison of manometric, radiographic and clinical findings. Gastroenterology 1991;101:743-8.

11 Jancovic J, Brin MF. Therapeutic use of botulinum toxin. $N$ Engl f Med 1991;324:1186-94

12 Cohen S, Parkman HP. Treatment of achalasia-from whalebone to botulinum toxin. N Engl f Med 1995;332: 815-16.

13 Pasricha PJ, Ravich WJ, Kalloo AN. Effects of intrasphincteric botulinum toxin on the lower esophageal sphincter in piglets. Gastroenterology 1993;105:1045-9.

piglets. Gastroenterology 1993;105:1045-9.
14 Castell DO, Katzka DA. Botulinum toxin for achalasia: to be or not to be? Gastroenterology 1996;110:1650-2.

15 Vaezi MF, Richter JE. Current therapy for achalasia. Comparison and efficacy. F Clin Gastroenterol 1998;27:21-35.

16 Vaezi MF, Richter JE, Wilcox CM, et al. Botulinum toxin versus pneumatic dilation in the treatment of achalasia: a randomised study. Gut 1999;44:231-9.

17 Fishman VM, Parkman HP, Schiano TD, et al. Symptomatic improvement in achalasia after botulinum injection of the lower esophageal sphincter. Am $\mathcal{F}$ Gastroenterol 1996; 91:1724-30.

18 Jancovic J. Botulinum toxin in movement disorders. Curr Opin Neurol 1994;7:358-66.

19 Brin ME. Botulinum toxin: chemistry, pharmacology, toxicity and immunology. Muscle Nerve 1997; (suppl 7):S146-68.

20 Greene P, Fahn S, Diamond B. Development of resistance to botulinum toxin type A in patients with torticollis. Mov Disord 1994;9:213-17. 